\title{
Analysis for Error Patterns of Consonant-Vowel Combinations in Hearing-Impaired Elderly
}

\author{
Sihun Park ${ }^{1,2}$, Woojae Han ${ }^{1,2,3}$ \\ ${ }^{1}$ Laboratory of Hearing and Technology, ${ }^{2}$ Division of Speech Pathology and Audiology, ${ }^{3}$ Research Institute of Audiology and Speech Pathology, \\ College of Natural Sciences, Hallym University, Chuncheon, Korea
}

Received: April 26, 2020

Revised: May 29, 2020

Accepted: May 29, 2020

\section{Correspondence:}

Woojae Han, PhD

Laboratory of Hearing and Technology,

Division of Speech Pathology and

Audiology, Research Institute of Audiology and Speech Pathology, 8603 Natural Science Building, Hallym University, 1 Hallymdaehak-gil, Chuncheon 24252, Korea

Tel: +82-33-248-2216

Fax: +82-33-256-3420

E-mail:woojaehan@hallym.ac.kr
Purpose: Many previous studies related to speech recognition of hearing-impaired elderly have found that the elderly have difficulty in monosyllable recognition under noisy situations, but there is still lack of their specific information to perceive the monosyllables in terms of error pattern. The purpose of the present study was to measure and analyze the prominent errors of consonant (C)vowel $(V)$ combinations as a function of noise levels in the hearing-impaired elderly. Methods: A total of twenty older adults with sensorineural hearing loss participated. While randomly presenting 122 syllables which consisted of the Korean CV and VC combinations under quiet and two signalto-noise ratios (SNRs, +6 and $+3 \mathrm{~dB}$ ) conditions, the participants were asked to respond the syllables heard in a way of either discrimination or identification. Error rate (or percent incorrect) and error patterns of the syllables were analyzed in each condition. Results: Substitution error of the initial consonant showed the highest rate regardless of the background conditions. As the medial phoneme, the vowel errors were decreased as the level of noise increased. In the final consonant, additional error rate of $/ \mathrm{k} /$ was abruptly increased as SNR decreased. Furthermore, it was an interesting pattern that the initial consonants such as $/ \mathrm{s} /, \mathrm{I} / \mathrm{I}$, and $/ \mathrm{t}^{*} /$ had a high substitution error rate when combined with /i/, /O/, and / $\varepsilon /$ vowels, respectively. Conclusion: Based on the current results, the hearing-impaired older adults seem to have their unique error patterns although there is individual difference. We expect that these results will be fundamental data to understand characteristics of speech perception in the older adults at the monosyllables level.

Key Words: Consonant-vowel, Elderly with hearing loss, Monosyllable recognition, Recognition error, Error pattern.

\section{INTRODUCTION}

최근 통계청 자료에 따르면 국내의 전체 인구 중 고령 인구가 차지하는 비율은 약 $15.7 \%$ 로서 우리나라는 2017년부터 이미 고령 사회로 진입하였고(Statistics Korea, 2019), 증가하는 고령 인구 수와 더불어 노인성 난청 인구도 빠르게 증가하고 있다. 글자 그대로 청각 기관의 노화로 인해 발생하는 난청을 일컫는 '노인성 난청(aged hearing loss or presbycusis)'은 청력 역치의 상승과 함께 음향 자극의 처리 저하로 인해 어음 변별력이 떨어 지는 증상을 나타낸다(Gates \& Mills, 2005). 특히 노인성 난청 은 연령의 증가에 따라 난청율이 함께 상승하고(Brant \& $\mathrm{FO}^{-}$ zard, 1990), 남성이 여성에 비해 높은 발병률을 보이며(Davis,

(c) This is an Open Access article distributed under the terms of the Creative Commons Attribution Non-Commercial License (https://creativecommons.org/licenses/by-nc/4.0) which permits unrestricted non-commercial use, distribution, and reproduction in any medium, provided the original work is properly cited.
1995), 고주파수에서 대칭적인 감각신경성 난청의 형태를 보인 다(Davis, 1995). 난청이 있는 노인들은 일반적으로 소음 속 어 음인지에서 어려움을 겪으며(Parthasarathy et al., 2019), 특히 하나의 음절로 이루어진 단음절어를 인지하는 데 큰 어려움을 갖는다(Barona et al., 2019; Humes et al., 1991; van Rooij \& Plomp, 1990). 이러한 노인성 난청의 특징을 많은 연구자들은 중추 신경계의 청각처리 능력 저하와 함께 음소 회귀 현상의 부 정적 결과로 보고하였다(Kim \& Yeo, 2015; Parthasarathy et al., 2019). 따라서 노인들은 가청 능력 이외에도 인지적 요소의 영향으로 인해 실제 손실된 청력의 정도에 비해 훨씬 더 저하 된 어음인지 능력을 보고한다(Joo \& Jang, 2009).

Noh \& Chae(2001)의 연구에서는 난청인들의 실제 말소리의 이해 정도가 단어의 주파수별 분포 및 분석 결과와 일치하지 않음을 지적하였다. 즉, 가청력에 기반한 어음인지 능력은 난청 인마다 다르게 나타날 수 있으며(Baddeley, 1992; Han \& Al- 
len, 2012a, 2012b; No \& Lee, 2012), 대칭형의 감각신경성 난 청 환자들 중 다수에서 자음지각 능력이 상이하게 나타남을 여 러 선행연구들을 통하여 확인할 수 있다(Han \& Allen, 2012a; No \& Lee, 2012). 즉, 평균적인 정답률이 검사 대상자의 어음인 지 능력으로 간주되어 임상에서 실시하는 어음인지도(word recognition score, WRS)검사가 감각신경성 환자들의 실제 어 음인지 능력을 과소 혹은 과대 평가로 이어질 수 있다고 제안하 였다(Baddeley, 1992).

이를 위한 실질적인 해결 방안 중 하나로써, 평균 정답률의 관점이 아닌 오답률을 계산하고 그 오답들을 이루는 오류 간 규칙들을 분석하여 난청인들의 어음인지 능력을 측정하려는 연구가 시도되거나(Chun et al., 2015; Lee \& Kim, 2011), 청능 재활을 보다 효율적으로 실시하기 위해 난청인에서 빈번하게 범 하는 오류를 분석한 연구들도 진행되었다(Na et al., 2016; No \& Lee, 2012). 이러한 오류 패턴을 분석한 선행연구들의 공통적 인 결과들을 정리하면 고주파수의 감각신경성 난청 환자들은 대체로 단음절 중 초성에서 높은 오류율을 나타냈고(Lee \& Lee 2010; No \& Lee, 2012), 초성의 파열음, 폐쇄음, 마찰음이 포함된 단어들 간 구별이 어려웠으며, 특히 / / 모음과 연결된 일 음절어를 변별하는 데 많은 오류를 보여주었다(No \& Lee, 2012; Turner \& Cummings, 1999). 한편, 인공와우 및 보청기를 사용하는 난청 환자들의 오류 패턴을 분석한 Lee \& Kim(2011) 과 Chun et al.(2015)의 연구에서는 단음절 중 종성에서 높은 오류율이 나타났지만 배경 소음의 정도가 증가함에 따라 무응 답 오류 유형이 급격하게 증가하는 등 두 연구에서 비교적 일 관적인 패턴을 보고하였다.

그럼에도 국내의 오류율 및 오류 패턴에 관한 선행연구들은 저하된 인지적 요소를 지닌 노인성 난청 환자들의 하위군에서 차별화된 특징을 보고하지 못함은 물론 감각신경성 난청 환자 들의 오류 유형을 일반화하기에도 다소 문제점이 있다. 첫째, 소수의 연구자들에 의해 진행된 주제임에도 불구하고 일부 논 문들 간 상이한 결과를 보고하였다. 예를 들어 $/ \mathrm{u} /$ 모음과 연결 된 일음절어에서 오류 패턴을 분석한 Lee \& Lee(2010)의 연구 와 / / / 모음과 연결된 일음절어에서 오류 패턴을 정리한 Noh \& Chae(2001)의 연구는 결합된 모음이 상이하여 오류 패턴의 직 접적 비교가 어렵고, 제시한 어음을 음소 관점에서 오류 패턴 을 확인하였거나 음절 관점에서의 오류율만을 확인하는 등 분 석 방법에서도 연구들 간 일관성이 부족하여 통일된 결론을 얻 기가 어렵다. 둘째, 어음을 제시하는 데 있어서 적은 반복성 혹 은 일회성 검사로 인해 수집된 자료들은 난청 환자들이 일상 생활에서 겪는 오류 패턴을 대표하기에 한계가 있다. 셋째, 고 주파수 경사형의 청력도를 갖는 난청인들을 대상으로 오류 패 턴을 체계적으로 분석한 No \& Lee(2012)의 연구 결과는 가청
력과 어음인지 능력에서 일치성이 부족한 난청 노인들에게 재 활적 적용을 하기에도 한계가 있다. 넷째, 각각의 음소의 오류율 과 패턴을 확인하여 모음과의 결합으로 인해 나타나는 오류율의 증감을 확인한 국외 선행연구도 일부 있으나(Turner \& Cummings, 1999), 사용된 언어가 한국어가 아니기에 국내의 연구 결 과와 직접적으로 비교하거나 임상적으로 그대로 적용하기에는 문제점이 있다.

따라서 본 연구에서는 감각신경성 난청을 지닌 노인들이 인 지하는 데 어려움을 보이는 일음절어를 다양한 배경 소음의 정 도에 따라 여러 차례 무작위 반복적으로 제시한 후 두드러진 오류 패턴의 규칙을 확인하고자 한다. 또한 높은 오류율을 보 인 음소의 위치 및 유형을 분석하여 노인성 난청을 지닌 환자 들이 음소 간 결합 시 보고하는 오류 패턴은 물론 오류율의 증 감에 대해 체계적으로 분석하고자 한다. 본 연구의 의미 있는 결과는 난청 노인들의 어음인지의 오류에 대한 프로파일 자료 는 물론 추후 노인성 난청의 재활을 위해서도 기초 자료로 사 용될 수 있다.

\section{MATERIALS AND METHODS}

\section{연구 대상}

평균 연령 $74.25 \pm 3.49$ 세인 만 65 세 이상의 노인 20명(남성: 8 명, 여성: 12 명)이 본 연구에 참여하였다. 연구 대상자는 모두 보청기를 착용하지 않는 중도에서 중고도의 감각신경성 난청을 지녔다. 구체적으로 순음청력검사의 결과에서 $250,500,1,000$ $\mathrm{Hz}$ 의 저주파수 평균 역치는 우측 귀 $22.58 \pm 9.76 \mathrm{~dB} \mathrm{HL}$, 좌 측 귀 $21.75 \pm 10.45 \mathrm{~dB}$ HL이었고, $2,000,4,000,8,000 \mathrm{~Hz}$ 의 고주파수 평균 역치는 우측 귀 $43.08 \pm 18.60 \mathrm{~dB} \mathrm{HL}$, 좌측 귀 $42.92 \pm 18.62 \mathrm{~dB}$ HL이었다. 대상자의 쾌적역치수준(most comfortable level)은 $63.75 \pm 2.22 \mathrm{~dB} \mathrm{HL}$ 이었으며, WRS 결 과는 $93.47 \pm 10.57 \%$ 였다. 고막운동도검사에서 모든 대상자들 은 A-type 유형의 정상 결과를 나타냈고, 과거 이과적 병력이 나 특별한 수술 이력은 없는 것으로 자가 보고하였다. 치매 선별 용 간이정신상태검사-mini-mental state examination (MMSE)dementia screening] (Han et al., 2010) 수행 결과 대상자 모두 정상 기준인 25점 이상의 점수(평균: $28.10 \pm 1.12$ 점)를 받았다.

모든 연구 대상자들은 연구 목적 및 절차에 대하여 충분한 설 명을 듣고 이해한 후 연구 참여에 대한 동의서에 서명을 하였다.

\section{연구 장비 및 재료}

한국어의 자음(consonant)-모음(wowel) (CV)과 모음-자음 (VC)의 모든 조합으로 구성된 총 122 개의 일음절어를 여성 전문 아나운서에 의해 스튜디오에서 녹음한 후 root mean square 등 
기초적인 음향적 특징을 정리하였다. 본 연구에서 사용된 일음 절어의 종류는 Appendix에 정리하였다.

녹음된 자극음은 노인용 청능훈련 시스템인 Hearing $\mathrm{Re}^{-}$ habilitation for Older Adults (HeRO) (v.1.5.3, Laboratory of Hearing and Technology, Chuncheon, Korea)를 활용하여 무 작위로 제시하였다. 연구 대상자는 동일하게 제공받은 7-inch 의 tablet-PC (SM-T280, Samsung, Suwon, Korea)를 사용하 였으며, 각 연구 대상자는 자극음을 듣기에 편안한 강도를 직 접 설정할 수 있도록 안내받았다.

자극음은 기본적으로 일음절어 세 쌍을 순차적으로 제시하 였지만, 변별과 확인 검사로 세분화하여 보다 정교하게 일음절 어 인지도를 측정하였다. 즉, 변별 검사에서는 제시된 세 개의 일음절어가 같은지 다른지를, 다르다면 몇 번째 음이 다른지 판 단하도록 하였다. 확인 검사에서는 두 개의 동일한 일음절어가 제시되고 하나의 다른 일음절어가 제시될 때, 다른 소리로 인지 되는 일음절어를 직접 tablet-PC에 입력하도록 요청하였다. 일 음절어는 난이도에 따라 소음이 없는 조용한 상황과 2가지 신 호대잡음비[signal-to-noise ratio (SNR); $+6 \mathrm{~dB},+3 \mathrm{~dB} \mathrm{SNR}$ ] 로 구성된 백색 소음을 제시하였다.

실험에 참여하기 전 모든 연구 대상자들은 $\mathrm{HeRO}$ 시스템과 tablet-PC의 사용법에 대하여 충분한 교육을 받았다. 실험 과 정에서 매일 30 45분씩 7일간 총 122 개의 $\mathrm{CV}$ 와 $\mathrm{VC}$ 조합의 일 음절어를 변별과 확인 방식으로 수행하였고, 연구자는 대상자
가 변별과 확인 훈련의 다양한 난이도를 골고루 수행하고 있는 지를 주기적으로 확인하였다. 그러나 오류에 대한 피드백이 연 구 대상자의 정확도와 언어적 향상 능력에 대한 부적절한 영향 을 줄 수 있다는 Guntherova(2019)의 주장에 근거하여 검사 결 과에 대한 피드백은 제공하지 않았고, 연구자는 대상자의 실험 과정에 최소한으로 개입하도록 노력하였다.

\section{자료 수집 및 분석}

총 20명의 연구 대상자의 실험 결과는 Amazon EC2 (Amazon, Seattle, WA, USA) 웹서버에 실시간으로 축적되었고 검 사자는 MariaDB (v.10.4, MariaDB Foundation, Redwood city, CA, USA)와 MySQL 프로그램(v.1.1.7, Oracle Corporation, Redwood city, CA, USA)을 사용하여 데이터베이스에 축 적된 결과들을 추출하고 분석하였다.

자료 분석 절차는 다음의 세 가지로 진행하였다. 첫째, 제시 된 전체 일음절어의 대치, 첨가, 생략의 전체적인 오류율과 난 이도별 변화를 분석하고 음소의 오류 패턴을 확인하였다(Chun et al., 2015; Lee \& Kim, 2011; No \& Lee, 2012). 둘째, 음소의 위치에 따른 오류율을 확인하여 높은 오류율을 보인 오류의 유형을 파악하였다(Lee \& Kim, 2011; No \& Lee, 2012; Noh \& Chae, 2001). 셋째, 분석된 오류의 유형을 바탕으로 음소 간 결 합으로 발생되는 오류율의 증감에 대해 분석하였다.

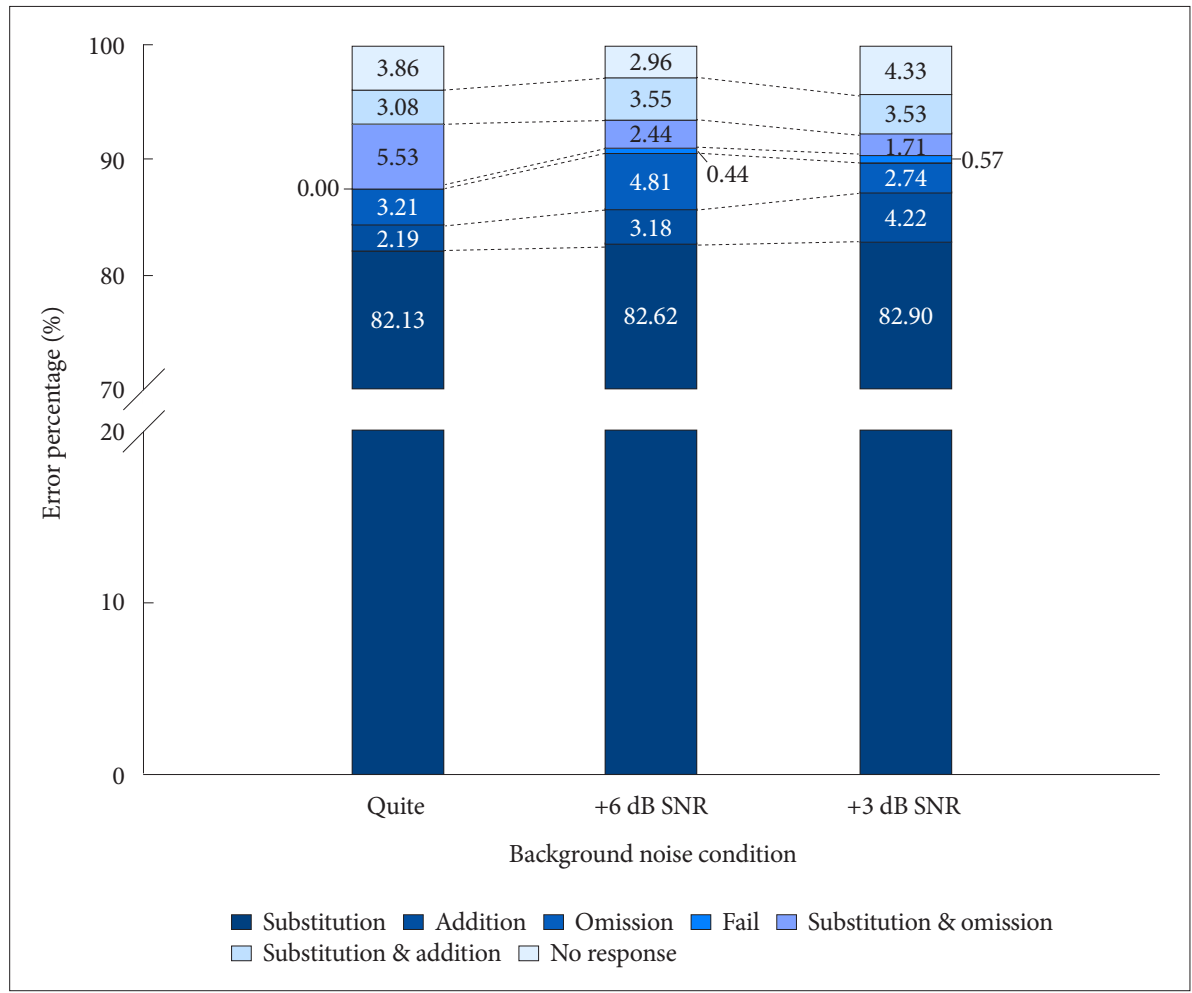

Figure 1. Comparison between error percentage of seven error patterns based on the consonant-vowel and vowel-consonant combinations as a function of background noise levels in 20 older adults with sensorineural hearing loss. SNR: signal-to-noise ratio. 


\section{RESULTS}

총 19,540 개의 결과가 데이터베이스에 축적되었다. 즉, 연구 대상자 1 인당 각 일음절어가 평균 $8.01 \pm 0.70$ 회 무작위 반복 제 시되었다. 조용한 상황, $+6 \mathrm{~dB}$ 과 $+3 \mathrm{~dB} \mathrm{SNR}$ 의 소음 상황에서 20 명의 중도와 중고도의 감각신경성난청 노인들의 일음절어의 평 균 오류율은 각각 $14.97 \pm 6.73 \%, 18.58 \pm 7.03 \%, 11.91 \pm 5.81 \%$ 였다. 검사에 사용된 각 일음절어에 대한 난이도별 오류율은 Appendix에 정리하였다.

\section{신호대잡음비에 따른 일음절어의 오류 유형}

Figure 1은 신호대잡음비에 따른 일음절어의 오류율을 $100 \%$ 로 재계산하여 오류 패턴들을 정리하였다. 오류 패턴의 유형은 총 7가지로 대치, 첨가, 생략, 실패, 대치와 생략, 대치와 첨가, 무 응답으로 범주화하였다. 가장 많은 오류를 보인 유형은 대치였 으며, 모든 검사 난이도에서 약 $82 \%$ 이상의 높은 오류율을 보였 다. 실패와 첨가에 대한 오류율은 조용한 상황에서 각각 $0 \%$ 와 $2.19 \%$ 였으나, 배경 소음이 증가함에 따라 $+3 \mathrm{~dB}$ SNR 상황에서 는 $0.57 \%$ 로, 약 $4.22 \%$ 로 증가하였다.

\section{신호대잡음비에 따른 일음절어의 오류 패턴}

배경 소음 정도에 따라 자모음의 대치 오류 패턴을 분석하였 다. Figure 2는 가로축을 기준으로 좌측부터 소음이 없는 조용 한 상황과 $+6 \mathrm{~dB}$ 과 $+3 \mathrm{~dB}$ SNR 상황에서 오류 패턴의 변화를 보여주며, 세로축을 기준으로 가장 위에서부터 초성, 중성, 종 성의 결과를 제시하였다. No \& Lee(2012)의 연구에서는 대상 자의 실수로 인한 연구 데이터 오염을 방지하기 위하여 2회 이 상의 오류를 보인 결과만을 데이터에 포함하여 분석하였다. 본 연구에서도 동일한 이유와 정확한 시각적 분석을 위해, 1 회 혹 은 2회의 비반복적인 혹은 아주 적은 수의 오반응은 연구 대상 자의 실수 또는 미숙한 사용 등으로 간주하여 데이터에서 제외 되었다. 결과적으로 조용한 상황과 $+3 \mathrm{~dB} \mathrm{SNR}$ 상황에서는 3회 미만, $+6 \mathrm{~dB} \mathrm{SNR}$ 의 조건에서는 4 회 미만의 데이터가 제외되어 서 약 $0.7 \%$ 이상의 오류율을 보이는 결과만이 참 반응(true response)으로 분석되었다.

초성 자음의 경우 조용한 상황에서는 /시의 대치 오류율이 $10.74 \%$ 로 가장 높았으며, $+6 \mathrm{~dB}$ 과 $+3 \mathrm{~dB}$ SNR 상황에서는 각 각 /리과 /ᄄᄄ /이 $8.45 \%, 11.70 \%$ 의 오류율을 보여 가장 높은 결과 를 보여주었다. 한편 /리의 음소가 초성에 위치하는 경우 /ㄴ/으

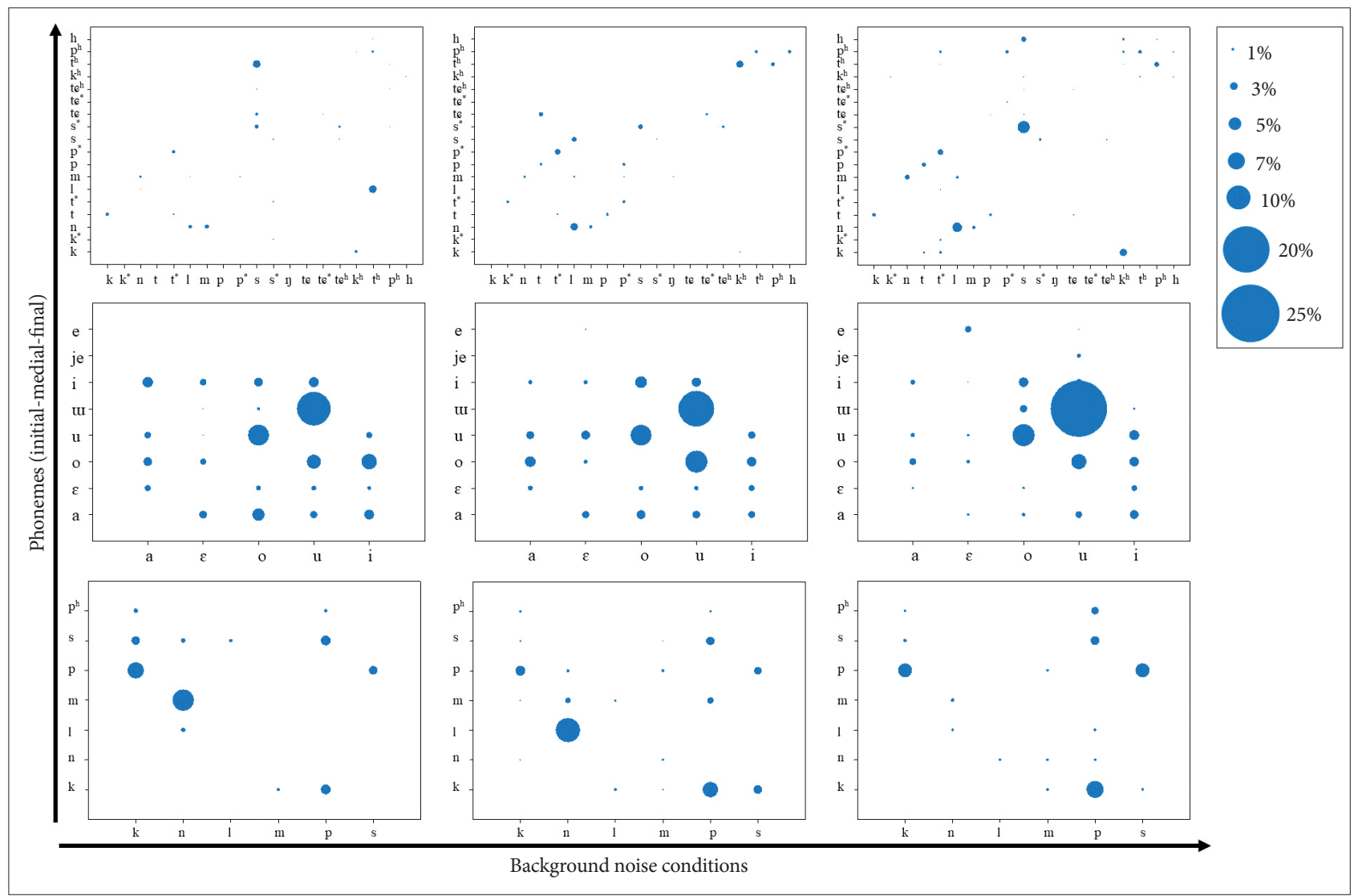

Figure 2. Substitution error patterns of phonemes as a function of SNR. Upper, medial, and bottom panels are initial, medial, and final phonemes, respectively. Left, middle, and right panels are quiet, $+6 \mathrm{~dB}$ and $+3 \mathrm{~dB}$ SNR, respectively. SNR: signal-to-noise ratio. 
로 인식하는 오류를 모든 상황에서 빈번하게 보였는데, 조용한 상황과 두 가지 신호대잡음비 상황에서 각각 $1.92 \%, 3.65 \%$, $4.46 \%$ 의 결과를 보였다. 즉, 배경 소음의 정도가 증가함에 따라 오류율이 증가하였다. 모음의 경우 조용한 상황과 두 가지 신호 대잡음비 상황에서 공통적으로 대치 오류율이 높았던 음소는 / T/로서 조용한 상황과 $+6 \mathrm{~dB}$ 과 $+3 \mathrm{~dB} \mathrm{SNR}$ 상황에서 각각 $32.16 \%, 36.21 \%, 41.39 \%$ 의 결과를 보였다. 그중 / $T /$ 를 / _ / 로 인식하는 대치 오류를 모든 상황에서 가장 빈번하게 보였으며, 신호대잡음비가 낮아짐에 따라 각각의 오류율은 $15.14 \%$, $16.02 \%, 25.19 \%$ 로 급격히 증가하였다. 종성의 경우 조용한 상황 에서 /ㄴ/의 대치 오류율이 $23.81 \%$ 로 가장 높았으며, $+6 \mathrm{~dB}$ $\mathrm{SNR}$ 상황에서는 /ㄴ/과 /비의 대치 오류율이 동일한 값으로 $25.38 \%$ 의 결과를 보여 가장 높았다. $+3 \mathrm{~dB}$ SNR 상황에서는 / 비이 $35.40 \%$ 의 높은 대치 오류율을 보였다. 이 중 전체적으로 /비의 음소를 / 기으로 인식하는 오류를 가장 많이 보였으며, 조용한 상황과 두 가지 신호대잡음비 상황에서 각각 $4.55 \%$, $7.03 \%, 7.73 \%$ 의 오류율을 보여 신호대잡음비가 낮아짐에 따라 오류율이 증가하였다. 반면 /ㄴ/의 음소를 /미으로 인식하는 오 류는 이와는 다른 양상을 보였다. 즉, 배경 소음의 정도가 높아 짐에 따라 $9.66 \%, 2.75 \%, 1.82 \%$ 로 감소하는 결과를 보였다.

조용한 상황과 2 가지의 신호대잡음비 상황에서 초성, 중성 종성의 공통적인 대치 오류를 보인 음소는 Table 1에 요약하였 다. 초성의 대치 오류에서 신호대잡음비가 낮아짐에 따라 오류 율이 증가한 음소는 /ㄹ/ $\rightarrow /$ / /, /ㄹ/ $\rightarrow /$ ㅁ/, / / ㄱ/ $\rightarrow /$ ㅆ/, / E/ $\rightarrow /$ 피/, $/$ 피 $\rightarrow / E /$ 이었고, 종성의 경우 신호대잡음비가 낮아짐에 따라 오류율이 증가한 음소는 /ㅂ/ $\rightarrow / 7 /$ 이었으며, 오류율이 감소한 음소는 /ㄴ/ $\rightarrow /$ ㅁㅇ이었다. 모음의 경우 신호대잡음비가 낮아짐에 따라 오류율이 증가한 음소는 / / / $/ / / / / / / \rightarrow / T /$ 였으며, 감소

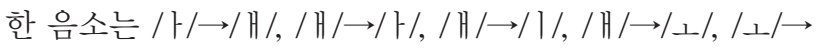
$/ / /, / \perp / \rightarrow / / /, / T / \rightarrow / / /, / / / \rightarrow /$ / / 였다. 모음은 대체적으로 신 호대잡음비가 낮아짐에 따라 오류율이 감소하였으며, 특히 / / / 음소의 오류 비율이 상당수 감소하였다.

배경 소음 정도에 따라 초성에서 첨가의 오류를 보인 데이터 를 확인한 결과, 모든 신호대잡음 상황에서 공통점은 확인되지 않았다. 그러나 종성의 경우 조용한 상황에서 / ㄱ/, /ㅁ/, /ㅂ/, / ㅇ/ 의 오류율이 각각 $7.39 \%, 2.84 \%, 3.41 \%, 1.70 \%$ 로 나타났고, +6 $\mathrm{dB}$ SNR 상황에서는 / ᄀ//, /ㄴ/, /ㄹ/, /ㅁ/, /ㅂ/, /ㅅ/, /이의 오류 율이 각각 $8.56 \%, 2.14 \%, 2.14 \%, 3.98 \%, 1.53 \%, 1.83 \%, 1.22 \%$ 로 나타났으며, $+3 \mathrm{~dB} \mathrm{SNR}$ 상황에서는 / ᄀ/, /ㄴ//, /ㄹ/, /ㅂ/의 오류율이 각각 $17.73 \%, 1.82 \%, 1.82 \%, 3.18 \%$ 로 확인되었다. /ᄀᄀ/ 과 /비의 첨가가 모든 신호대잡음비 상황에서 공통적인 오류 로 나타났으며, 이 중 / ᄀ//의 음소는 신호대잡음비가 낮아짐에 따라 종성 첨가 오류율이 급격히 증가하였다.
Table 1. Substitution error type and its error percentage that 20 old listeners had commonly as a function of SNR

\begin{tabular}{|c|c|c|c|c|}
\hline \multirow{2}{*}{ Stimulus } & \multirow{2}{*}{ Response } & \multicolumn{3}{|c|}{ Background noise conditions } \\
\hline & & Quiet & $+6 \mathrm{~dB}$ SNR & $+3 \mathrm{~dB}$ SNR \\
\hline \multicolumn{5}{|c|}{ Initial consonant } \\
\hline $\mathrm{n}$ & $\mathrm{m}$ & 1.37 & 1.27 & 2.35 \\
\hline \multirow[t]{2}{*}{1} & $\mathrm{n}$ & 1.92 & 3.65 & 4.46 \\
\hline & $\mathrm{m}$ & 0.82 & 0.95 & 1.41 \\
\hline $\mathrm{m}$ & $\mathrm{n}$ & 2.20 & 1.59 & 1.64 \\
\hline s & $s^{*}$ & 2.20 & 2.38 & 5.63 \\
\hline $\mathrm{s}^{*}$ & s & 1.10 & 0.79 & 1.41 \\
\hline $\mathrm{k}^{\mathrm{h}}$ & $\mathrm{k}$ & 1.65 & 0.95 & 3.52 \\
\hline $\mathrm{t}^{\mathrm{h}}$ & $\mathrm{p}^{\mathrm{h}}$ & 1.37 & 1.59 & 1.88 \\
\hline $\mathrm{p}^{\mathrm{h}}$ & $\mathrm{t}^{\mathrm{h}}$ & 0.82 & 1.90 & 2.35 \\
\hline \multicolumn{5}{|l|}{ Medial vowel } \\
\hline \multirow[t]{4}{*}{ a } & $\mathrm{i}$ & 4.86 & 2.16 & 2.31 \\
\hline & o & 4.05 & 4.93 & 3.34 \\
\hline & $\mathrm{u}$ & 3.24 & 3.85 & 2.06 \\
\hline & $\varepsilon$ & 2.97 & 2.47 & 1.03 \\
\hline \multirow[t]{4}{*}{$\varepsilon$} & $\mathrm{a}$ & 3.78 & 3.54 & 1.29 \\
\hline & $\mathrm{i}$ & 3.24 & 2.00 & 0.77 \\
\hline & o & 2.97 & 2.00 & 1.80 \\
\hline & $\mathrm{u}$ & 0.81 & 4.16 & 1.29 \\
\hline \multirow[t]{3}{*}{ o } & $\mathrm{u}$ & 9.46 & 9.40 & 10.03 \\
\hline & $\mathrm{a}$ & 5.68 & 4.16 & 1.80 \\
\hline & $\varepsilon$ & 2.43 & 2.31 & 1.29 \\
\hline \multirow[t]{4}{*}{$\mathrm{u}$} & u & 15.14 & 16.02 & 25.19 \\
\hline & o & 6.49 & 10.02 & 6.94 \\
\hline & $\mathrm{i}$ & 4.59 & 4.31 & 3.08 \\
\hline & a & 3.51 & 3.70 & 3.34 \\
\hline \multirow[t]{4}{*}{$\mathrm{i}$} & o & 7.03 & 4.47 & 4.37 \\
\hline & $\mathrm{a}$ & 4.59 & 3.39 & 4.11 \\
\hline & $\mathrm{u}$ & 2.97 & 3.54 & 4.63 \\
\hline & $\varepsilon$ & 1.89 & 2.93 & 2.83 \\
\hline \multicolumn{5}{|c|}{ Final consonant } \\
\hline \multirow[t]{3}{*}{$\mathrm{k}$} & $\mathrm{p}$ & 7.39 & 4.59 & 6.36 \\
\hline & s & 3.98 & 0.92 & 1.82 \\
\hline & $\mathrm{p}^{\mathrm{h}}$ & 2.27 & 1.22 & 1.36 \\
\hline \multirow[t]{2}{*}{$\mathrm{n}$} & $\mathrm{m}$ & 9.66 & 2.75 & 1.82 \\
\hline & 1 & 2.27 & 11.01 & 1.36 \\
\hline $\mathrm{m}$ & $\mathrm{k}$ & 1.70 & 0.92 & 1.36 \\
\hline \multirow[t]{3}{*}{$\mathrm{p}$} & $\mathrm{k}$ & 4.55 & 7.03 & 7.73 \\
\hline & s & 4.55 & 3.98 & 4.09 \\
\hline & $\mathrm{p}^{\mathrm{h}}$ & 1.70 & 1.22 & 3.64 \\
\hline s & $\mathrm{p}$ & 3.98 & 3.67 & 6.36 \\
\hline
\end{tabular}

SNR: signal-to-noise ratio

초성의 생략 오류는 조용한 상황에서 /TT/, /ㄴ/, /匹/, /ㄹ/, /ㅁ/, /ㅂ/, /삐/, / ㅅ/, /ㅈ/, /E/, /피/의 오류율이 각각 1.92\%, 1.37\%, $1.65 \%, 1.37 \%, 1.10 \%, 1.37 \%, 0.82 \%, 1.37 \%, 0.82 \%, 1.37 \%$, $0.82 \%$ 로 확인되었고 $+6 \mathrm{~dB}$ SNR 상황에서 / ᄀ /, / T/, / ᄃ/, /삐/, 
/지의 오류율이 각각 $0.95 \%, 0.95 \%, 0.95 \%, 0.79 \%, 4.29 \%$ 로 나 타났으며, +3 dB SNR 상황에서 /ㄴ/, /ㄹ/, / ㅁ/, /삐/의 오류율이 각각 $0.70 \%, 0.94 \%, 1.88 \%, 1.41 \%$ 로 나타나 공통적인 오류를 보 인 음소는 /삐이었다. 초성의 생략 오류는 신호대잡음비가 낮 아짐에 따라 음소의 수와 오류율이 감소하는 패턴을 보여주었다. 종성의 생략 오류는 조용한 상황에서 / ᄀ /, /ㄴ/, /ㄹ/, /ㅁ/, /ㅂ/, /시, / / / 의 오류율이 각각 3.41\%, 2.84\%, 2.84\%, 2.84\%, 5.11\%, $2.27 \%, 2.84 \%$ 로 나타났고, $+6 \mathrm{~dB}$ SNR 상황에서 / ㄱ/, / ㄴ/, /ㄹ/, /ㅁ/, /비, / / 싀의 오류율이 각각 4.59\%, 3.67\%, $1.22 \%, 3.98 \%$, $2.45 \%, 2.45 \%$ 로 확인되었으며, +3 dB SNR 상황에서 /ㄴ/, /ㄹ/, /ㅁ/, /ㅂ/, / ㅅ/, / / / 의 오류율이 각각 $5.45 \%, 2.27 \%, 3.64 \%$, $3.64 \%, 3.18 \%, 3.64 \%$ 로 나타나 공통적으로 /ㄴ/, /ㄹ/, /ㅁ/, /ㅂ/, /ㅅ/의 음소에서 오류를 보였다. 이 중 /ㄴ/과 /ㅅ/의 음소가 신 호대잡음비가 낮아짐에 따라 종성의 생략 오류율이 증가하는 패턴으로 두드러졌다.

\section{신호대잡음비에 따른 음소의 위치의 오류 패턴 비교}

위치에 따른 오류율을 확인한 결과 조용한 상황에서 초성과 종성의 오류율은 각각 $67.41 \%, 32.56 \%$ 였다. $+6 \mathrm{~dB} \mathrm{SNR}$ 상황 에서는 초성 $65.83 \%$, 종성 $34.17 \%$ 의 오류율을 보였으며, $+3 \mathrm{~dB}$ SNR 상황에서는 초성 $65.94 \%$, 종성 $34.06 \%$ 의 오류율을 나타 내어, 초성 위치의 음소가 오류율이 훨씬 높은 것으로 확인되었 다. 초성의 오류 유형은 조용한 상황에서 대치, 첨가, 생략이 각 각 $81.87 \%, 1.92 \%, 16.21 \%$ 로 확인되었고, $+6 \mathrm{~dB}$ SNR 상황에서 는 $82.70 \%, 4.44 \%, 12.86 \%$ 로 확인되었다. $+3 \mathrm{~dB} \mathrm{SNR}$ 상황에 서는 $88.26 \%, 3.05 \%, 8.69 \%$ 로 분석되어 대치의 오류 유형이 가 장 많이 나타났으며, 신호대잡음비가 낮아짐에 따라 생략 오류 의 비율이 점차적으로 감소하였지만, 대치 오류율은 점차적으 로 증가하는 규칙을 확인하였다.

Table 2에서는 신호대잡음비에 따른 높은 초성 대치 오류율을 보인 5개의 음소를 순서대로 정리하였다. 공통적으로 /ㅅ/, /ㄹ/, /匹/의 음소가 높은 대치 오류율을 보이는 것으로 확인되었다.

\section{신호대잡음비에 따른 음소 간 결합 시 오류 패턴 분석}

Table 3은 공통적으로 높은 대치 오류를 보인 초성의 음소
간 결합으로 나타난 오류율을 보여준다. $20 \%$ 이상의 높은 오 류율을 나타내는 값을 기준으로 모든 신호대잡음 상황에서 공 통적으로 / 시의 음소가 /// 모음을 만나게 되면 다른 모음과 비교하여 오류율이 상대적으로 증가하였으며, /리의 음소가 /ㄱ/ 모음을 만날 경우에도 동일한 결과를 나타냈다. 또한 /ᄄ/의 음 소가 / / / 모음과 결합되면 다른 모음과 비교하여 오류율이 상 대적으로 증가하였으나, $+3 \mathrm{~dB} \mathrm{SNR}$ 상황에서는 이러한 규칙 은 분석되지 않았다.

\section{DISCUSSIONS}

본 연구는 20명의 중도와 중고도의 감각신경성 난청 노인 20명 을 대상으로 모바일 기반의 일음절어 검사를 실시하고, 신호대 잡음비에 따라 자모음 오류율 및 오류 패턴을 분석하였다. 또한 음소 간의 결합으로 인해 변화되는 오류율 증감과 그 패턴을 확인하였다.

본 연구 결과에서 사용된 전체 일음절어의 오류 유형들 중 대치가 모든 조건에서 약 $82 \%$ 이상으로 가장 두드러졌으며, 초 성의 대치 오류 패턴이 가장 빈번하게 확인되었다. 이는 감각신

Table 3. Analysis of error percentage of the initial consonant and medial vowel combinations in each condition

\begin{tabular}{ccrrr}
\hline \multirow{2}{*}{$\begin{array}{c}\text { Initial } \\
\text { cosonant }\end{array}$} & Medial & \multicolumn{3}{c}{ Background noise conditions } \\
\cline { 3 - 5 } vowel & Quiet & $+6 \mathrm{~dB}$ & $+3 \mathrm{~dB}$ \\
\hline $\mathrm{s}$ & $\mathrm{a}$ & 18.42 & 20.69 & 13.64 \\
& $\varepsilon$ & 8.51 & 19.35 & 10.77 \\
& $\mathrm{o}$ & 37.50 & 18.87 & 14.75 \\
& $\mathrm{u}$ & 15.56 & 21.82 & 14.75 \\
& $\mathrm{i}$ & 29.41 & 20.37 & 31.34 \\
$\mathrm{l}$ & $\mathrm{a}$ & 14.63 & 14.55 & 7.94 \\
& $\mathrm{o}$ & 21.74 & 38.36 & 21.88 \\
& $\mathrm{u}$ & 18.60 & 23.33 & 27.69 \\
& $\mathrm{i}$ & 24.32 & 28.07 & 14.04 \\
$\mathrm{t}^{*}$ & $\mathrm{a}$ & 17.78 & 15.15 & 14.94 \\
& $\mathrm{E}$ & 25.64 & 29.41 & 9.09 \\
& $\mathrm{o}$ & 11.11 & 12.73 & 9.68 \\
& $\mathrm{u}$ & 22.92 & 17.31 & 21.54 \\
& $\mathrm{i}$ & 18.92 & 29.79 & 18.57 \\
\hline
\end{tabular}

Table 2. Error percentage of the most frequent five phonemes for the substitution error of the initial consonant in each condition

\begin{tabular}{|c|c|c|c|c|c|}
\hline \multicolumn{2}{|c|}{ Quiet } & \multicolumn{2}{|c|}{$+6 \mathrm{~dB}$ SNR } & \multicolumn{2}{|c|}{$+3 \mathrm{~dB}$ SNR } \\
\hline Phoneme & Error rate $(\%)$ & Phoneme & Error rate (\%) & Phoneme & Error rate (\%) \\
\hline s & $21.88( \pm 11.53)$ & 1 & $26.08( \pm 9.92)$ & 1 & $17.89( \pm 8.68)$ \\
\hline $\mathrm{t}^{\mathrm{h}}$ & $20.96( \pm 7.41)$ & $\mathrm{k}^{\mathrm{h}}$ & $24.17( \pm 12.68)$ & $\mathrm{s}$ & $17.05( \pm 8.15)$ \\
\hline 1 & $19.82( \pm 4.18)$ & $t^{*}$ & $20.88( \pm 8.13)$ & $t^{*}$ & $14.76( \pm 5.44)$ \\
\hline$t^{*}$ & $19.27( \pm 5.54)$ & $\mathrm{p}^{*}$ & $20.33( \pm 7.32)$ & $\mathrm{k}^{\mathrm{h}}$ & $13.66( \pm 5.58)$ \\
\hline $\mathrm{p}$ & $15.06( \pm 6.11)$ & $\mathrm{s}$ & $20.22( \pm 1.16)$ & $\mathrm{p}^{\mathrm{h}}$ & $13.64( \pm 5.01)$ \\
\hline
\end{tabular}

SNR: signal-to-noise ratio 
경성 난청인을 대상으로 오류 패턴을 알아본 Lee \& Lee(2010) 의 연구에서도 약 $83 \%$ 의 대치 오류를 확인하여 본 연구의 결과 와 매우 일치하였다. 또한 가청력의 관점에서 $2,000 ~ 4,000 \mathrm{~Hz}$ 대 역의 주파수가 초성의 자음 지각과 관련이 있으며, $500 ~ 2,000 ~ H z$ 의 주파수 대역이 종성 자음을 지각하는 데 중요하다는 Ryu et al.(2011)의 연구가 이를 뒷받침한다. 이와 같은 근거를 바탕으 로 초성 대치 오류를 중점적으로 난청 노인들의 청능훈련을 실 시한다면 좀 더 효율적인 재활 효과를 기대할 수 있을 것으로 사료된다.

본 연구에서는 모든 신호대잡음비 상황에서 공통적으로 초성 자음의 대치 오류를 보인 음소는 /ㄴ/, /ㄹ/, /ㅁ/, /ㅅ//, /ㅆ/, /ㅋ/, /E/, /피/이었다. 고음역 난청의 오류율을 분석한 $\mathrm{Hahm(1963)}$ 의 연구에서는 초성 자음의 /ㅅ/, /ㅆ/, /ㅎ/, /피/, /E/이 높은 오 류율을 보인다고 보고하였다. 또한 Lee \& Lee(2010)의 연구에 서는 같은 주파수대의 자음들인 / ㅅ/, /ㅊ/, /E/ 중 /ㅊ/이 상대적 으로 인지도가 높다는 결과를 보여 상당 부분 본 연구와 일치하 였다. 이들 초성 자음의 음향학적 특성은 최고점 주파수가 3 $\mathrm{kHz}$ 이상의 고음역에 분포하는 공통점을 보인다(Noh \& Chae, 2001). 이는 가청력의 관점에서 고주파수 난청을 보이는 노인성 난청의 일반적인 어음인지의 결과로 보인다. 그러나 본 연구 결 과에서는 비교적 저주파수 대역의 /ㄹ/, / ㄴ/의 음소에서도 오류 가 관찰되어 앞서 서론에서 언급한 대로 가청력만으로 설명하 기 어려운 결과를 보여주었다. No \& Lee(2012)의 연구에서는 경사형과 수평형의 난청인을 대상으로 어음인지검사를 실시하 였고 모든 대상군에서/ㄴ/의 음소를 /ㅁ으로 대치하는 높은 오류를 보였다. 또한 건청인을 대상으로 말 지각 패턴을 알아본 Kwak et al.(2019)의 연구에서도 /ㄴ/ 음소의 오류율 중 /ㅁ/으 로 지각하는 높은 오류율을 보여, 건청인에게도 /ㄴ/의 /ㅁㅇㅡ 로의 오류는 빈번함을 알 수 있다. 안타깝게도 /리 음소의 경 우 본 연구 결과와 일치하는 국내의 선행연구는 확인되지 않았 다. 아마도 대부분의 연구에서 한국 표준 단음절어표를 사용했 는데, 두음법칙으로 인하여 초성에 /리 음소가 포함된 단음절 어가 단음절어표에 포함되지 않아 측정되지 않았기 때문(Byun et al., 2007)이라 판단된다. 본 연구에서 또한 두음법칙이 일어 나는 /리이 /니으로 대치되는 오류가 가장 많았다.

종성 자음에서 첨가 오류의 경우, 본 연구에서는 /ᄀᄀ/의 첨가 가 신호대잡음비가 낮아짐에 따라 크게 증가하였다. Lee \& Lee(2010)의 연구에서는 CV 음절을 검사 어음으로 사용하였 으며, /ᄀᄀ/, /ㅂ/, /ㄹ/을 첨가하여 인지하는 오류를 보였는데, 해 당 연구의 대상자가 대부분 60 80대의 고령 대상자였다. 따라 서 이는 노인성 난청을 가진 환자들에게서 두드러진 오류 패턴 으로 이해할 수 있겠다. 반면, 보조기기를 착용한 성인의 오류 패턴을 확인한 Chun et al.(2015)의 연구에서는 신호대잡음비
가 낮아짐에 따라 5 회에서 9 회로 증가하는 패턴을 보여 본 연 구의 결과와 유사하였다. 생략 오류의 경우에도 Chun et al.(2015)의 연구와 비슷한 패턴을 보였는데, 조용한 상황과 -6 $\mathrm{dB} \mathrm{SNR}$ 상황에서 각각 모음의 오류 빈도가 45회에서 26회로 감소하는 결과가 분석되어 신호대잡음비가 낮아짐에 따라 모 음의 오류율이 크게 감소하였다. 흥미롭게도 연구 대상자의 청 각적 배경 특성이 다름에도 불구하고 본 연구 결과와 동일한 패턴을 보였다. 다시 말해 난청 성인과 65 75세 난청 노인의 청 각처리 능력을 확인한 Humes \& Christopherson(1991)의 연구 에서는 음절 변별(syllable identification) 검사에서 각각 평균 45점과 48점의 점수를 보여 두 그룹 간의 차이가 없음을 보고 하였으며, 이 외의 tone pulse or rhythm discrimination, $\mathrm{du}^{-}$ ration discrimination, intensity discrimination 검사에서 비 슷한 수행력을 보였다. 해당 선행 논문의 결과를 바탕으로 대 상자의 상이함에도 불구하고 비슷한 결과가 도출된 이유는 노 인의 중추신경계 청각처리 저하로 인한 결과로 생각된다(Lunner, 2003). 이와 같은 결과는 가청력뿐만 아니라 대상자의 청 각처리 기능도 고려해야 함을 시사하며 후속연구를 통하여 좀 더 객관화되고 증명되어야 할 것이다.

배경 소음의 정도에 따른 높은 초성 대치 오류율을 보인 상 위 5 개의 음소들 중 공통적인 음소는 /ㅅ/, /ㄹ/, /匹/이었고, 그 각각은 / / / / / / / / / / 의 모음과 연결되었을 때 높은 오류율이 확인되었다. 선행연구들에 따르면 / / 모음과 연결된 일음절어 를 변별하는 데 많은 오류를 보인다고 보고하였다(No \& Lee, 2012; Turner \& Cummings, 1999). 고음역 난청에서 분별하기 어려운 단음절어의 음향을 분석한 Noh \& Chae(2001)의 연구 에서는 / / 모음이 중성으로 연결되었을 때 자음의 전이 주파 수가 평균적으로 4,329 $\pm 1,399 \mathrm{~Hz}$ 의 고음역으로 이동한다고 보고하였다. 선행연구의 결과와 본 연구의 결과는 가청력 부분 에서 일정 부분 불일치함을 확인할 수 있다. 그러나 5 개의 자음 과 3개의 모음을 연결하여 자모음 $(\mathrm{C}-\mathrm{V})$ 인지도를 확인한 Lee $\&$ Lee(2010)의 연구에서는 자음과 모음의 결합에 따라 어음인 지 점수가 모두 다르게 나타나는 패턴을 확인하였으며, 평균적 으로 /T/ 모음과의 연결이 어음인지 점수에서 가장 낮았다. 이 는 각각의 음소 간 결합 오류의 증감률을 좀 더 자세히 확인해 야 할 필요성과 평균적인 어음인지 점수가 집단의 특성을 대표 할 수 없다는 점을 다시 한 번 강조한다.

보건복지부의 보고서에 따르면 2008년 국내의 노인 중 약 $24.1 \%$ 가 인지기능 저하를 보이며, 약 $8.4 \%$ 가 치매 노인으로 추 정된다(Ministry of Health and Welfare, 2008). 인지기능 저하 는 정상과 치매의 중간 단계로서 MMSE 점수에서는 27 30점 의 정상 점수를 보임을 감안하고(O’Bryant et al., 2008), 앞선 보건복지부 보고서의 통계 수치를 기반으로 추정한다면 국내 
의 정상과 인지기능 저하 노인 환자의 비율을 고려하면 $91.6 \%$ 로 대부분의 노인을 포함하기에 중고도의 감각신경성 난청 노인 대상자의 공통적인 오류 패턴을 다수의 데이터를 확보하여 확 인한 본 연구의 결과를 일반화하기에는 문제가 없을 것으로 사 료된다. 그러나 본 연구는 저하된 인지력 정도와 일음절어 인지 간 직접적인 상관성을 확인하지 못했다는 한계점이 있다. 그럼 에도 기존 연구들이 가청력 중심의 오류 패턴을 분석하였다면, 본 연구에서는 가장 빈번한 중도-중고도의 약간의 경사형 감 각신경성 난청 노인들을 특화하여 여러 차례 검사하고 난청 노 인들의 일음절어 오류율과 그 오류 패턴을 체계적으로 분석했 다는 점과 음소 간의 결합 시 나타나는 오류율의 증감에 대해 새로운 자료를 제시하였다는 점에서 의미가 높다. 후속연구에 서는 의미 단위의 단어 및 문장에서도 오류 형태와 규칙을 체 계적으로 분석한다면 본 연구 결과와 함께 난청 노인들의 청능 훈련 및 청각 재활에 기초 자료로서 다양한 활용성을 기대할 수 있다.

중심 단어 : 자모음·난청 노인·일음절 인지·인지 오류·오류 패턴.

\section{Ethical Statement}

This study was approved by the Institutional Review Board of Hallym University (HIRB-2017-124).

\section{Acknowledgments N/A}

\section{Declaration of Conflicting Interests}

There are no conflict of interests.

\section{Funding}

This work was supported by the Ministry of Education of the Republic of Korea and the National Research Foundation of Korea (NRF-2018 S1A3A2074932).

\section{Author Contributions}

All authors designed the experiment together; S.P. collected and analyzed the data; S.P. wrote the draft of the manuscript and W.H. revised the manuscript as the final version. Also, the authors discussed the results together and implications and commented on the manuscript at each stage.

\section{ORCID iDs}

Sihun Park https://orcid.org/0000-0001-6085-2107

Woojae Han https://orcid.org/0000-0003-1623-9676

\section{REFERENCES}

Baddeley, A. (1992). Working memory. Science, 255(5044), 556-559.

Barona, R., Vizcaíno, J. A., Krstulovic, C., Barona, L., Comeche, C., Montalt, J., et al. (2019). Does asymmetric hearing loss affect the ability to understand in noisy environments? The Journal of International Advanced Otology, 15(2), 267-271.

Brant, L. J. \& Fozard, J. L. (1990). Age changes in pure-tone hearing thresholds in a longitudinal study of normal human aging. The Journal of the Acoustical Society of America, 88(2), 813-820.
Byun, S. W., Oh, S. H., Chae, S. W., Park, S. N., Shim, Y. J., \& Cho, K. K. (2007). Compromises between the frequencies of the colloquial phonemes and those of a new monosyllabic words list in Korean. Korean Journal of Otorhinolaryngology-Head and Neck Surgery, 50(7), 573-578.

Chun, H., Ma, S., Han, W., \& Chun, Y. (2015). Error patterns analysis of hearing aid and cochlear implant users as a function of noise. Journal of Audiology and Otology, 19(3), 144-153.

Davis, A. (1995). Hearing in Adults: The Prevalence and Distribution of Hearing Impairment and Reported Hearing Disability in the MRC Institute of Hearing Research's National Study of Hearing. London: Whurr Publishers Ltd.

Gates, G. A. \& Mills, J. H. (2005). Presbycusis. The Lancet, 366(9491), 11111120.

Güntherova, K. (2019). The effectiveness, advantages and disadvantages of error correction methods in writing in EFL classrooms. (Unpublished Doctoral dissertation). University of Bedfordshire, Luton.

Hahm, T. Y. (1963). Effects of earplug on the acoustic insulation and the articulation of the Korean speech. Korean Journal of Otorhinolaryngology-Head and Neck Surgery, 6(1), 33-42.

Han, J. W., Kim, T. H., Jhoo, J. H., Park, J. H., Kim, J. L., Ryu, S. H., et al. (2010). A normative study of the mini-mental state examination for dementia screening (MMSE-DS) and its short form (SMMSE-DS) in the Korean elderly. Journal of Korean Geriatirc Psychiatry, 14(1), 27-37.

Han, W. \& Allen, J. B. (2012a). Speech perception test of zero-error consonant-vowel syllables in presbycusis. Audiology, 8(2), 183-189.

Han, W. \& Allen, J. B. (2012b). A relationship of tone, consonant, and speech perception in audiological diagnosis. The Journal of the Acoustical Society of Korea, 31(5), 298-308.

Humes, L. E. \& Christopherson, L. (1991). Speech identification difficulties of hearing-impaired elderly persons: The contributions of auditory processing deficits. Journal of Speech and Hearing Research, 34(3), 686693.

Humes, L. E., Nelson, K. J., \& Pisoni, D. B. (1991). Recognition of synthetic speech by hearing-impaired elderly listeners. Journal of Speech and Hearing Research, 34(5), 1180-1184.

Joo, Y. \& Jang, H. (2009). Effects of frequency range and degree of hearing loss on word recognition in elderly listeners. Audiology, 5(1), 36-41.

Kim, S. H. \& Yeo, S. G. (2015). Presbycusis. Hanyang Medical Reviews, 35(2), 78-83.

Kwak, C., You, S., Han, W., Lee, D., Ma, S., Park, S., et al. (2019). Speech-perceptual map using confusing matrix and application of Shepard's law. Audiology and Speech Research, 15(2), 78-83.

Lee, J. H. \& Kim, J. H. (2011). Comparison of word and environmental sound recognition by cochlear implant and hearing aid users. Audiology, 7(1), 28-39.

Lee, S. Y. \& Lee, K. W. (2010). Effects of word recognition score as a function of consonant-to-vowel ratio (CVR) in Korean non-sense syllables. Audiology, 6(1), 25-29.

Lunner, T. (2003). Cognitive function in relation to hearing aid use. International Journal of Audiology, 42 Suppl 1, S49-S58.

Ministry of Health and Welfare. (2008). A Nationwide Survey on the Prevalence of Dementia in Korean Elders (Report No.: 11-1351000-000227-01). Sejong: Ministry of Health and Welfare.

Na, W., Kim, G., Kim, G., Lee, J., \& Han, W. (2016). Sentence recognition error of hearing-impaired elderly in background noise and time alteration: Case analysis. Audiology and Speech Research, 12(4), 280-288.

No, B. I. \& Lee, J. H. (2012). A comparison study of monosyllable recognition in listeners with sloping versus flat hearing loss types. Audiology, $8(1), 78-86$

Noh, H. \& Chae, S. (2001). Acoustic analyses of monosyllabic words which are difficult to discriminate in the high frequency hearing loss. Korean Journal of Otorhinolaryngology-Head and Neck Surgery, 44(7), 700706.

O’Bryant, S. E., Humphreys, J. D., Smith, G. E., Ivnik, R. J., Graff-Radford, N. R., Petersen, R. C., et al. (2008). Detecting dementia with the mini- 
mental state examination in highly educated individuals. Archives of Neurology, 65(7), 963-967.

Parthasarathy, A., Bartlett, E. L., \& Kujawa, S. G. (2019). Age-related changes in neural coding of envelope cues: Peripheral declines and central compensation. Neuroscience, 407, 21-31.

Ryu, H. D., Shim, H. Y., \& Kim, J. S. (2011). A study of the relation between Korean consonant perception test (KCPT) and hearing thresholds as a function of frequencies. Audiology, 7(2), 153-163.

Statistics Korea. (2019, March 28). Projected Population by Age Group (Korea). Korean Statistical Information Service (KOSIS). Retrived from
http://kosis.kr/statHtml/statHtml.do?orgId=101\&tblId=DT_1BPA003 \&vw_cd=\&list_id $=\& s c r I d=\& s e q N o=\& l a n g \_m o d e=$ ko\&obj_var_ $\mathrm{id}=\& \mathrm{itm} \_\mathrm{id}=\&$ conn_path=B1\&path=\%252Fconts $\% 252 \mathrm{FnsportalStats}$ \%252FnsportalStats_0102Body.jsp.

Turner, C. W. \& Cummings, K. J. (1999). Speech audibility for listeners with high-frequency hearing loss. American Journal of Audiology, 8(1), 47-56. van Rooij, J. \& Plomp, R. (1990). Auditive and cognitive factors in speech perception by elderly listeners. II: Multivariate analyses. The Journal of the Acoustical Society of America, 88(6), 2611-2624. 
APPENDIX

\section{Error Percentage (\%) of 20 Older Adults with Hearing Loss Obtained from All Consonant-Vowel and Vowel-Consonant Combinations as a Function of Signal-to-Noise Ratios}

\begin{tabular}{|c|c|c|c|c|c|c|c|c|c|c|c|c|c|c|c|c|}
\hline \multirow{2}{*}{$\begin{array}{c}\text { Initial } \\
\text { consonant }\end{array}$} & \multirow{2}{*}{$\begin{array}{l}\text { Medial } \\
\text { vowel }\end{array}$} & \multicolumn{3}{|c|}{ Noise level } & \multirow{2}{*}{$\begin{array}{l}\text { Initial } \\
\text { onsonant }\end{array}$} & \multirow{2}{*}{$\begin{array}{l}\text { Medial } \\
\text { vowel }\end{array}$} & \multirow{2}{*}{$\begin{array}{c}\text { Final } \\
\text { consonant }\end{array}$} & \multicolumn{3}{|c|}{ Noise level } & \multirow{2}{*}{$\begin{array}{c}\text { Initial } \\
\text { onsonant }\end{array}$} & \multirow{2}{*}{$\begin{array}{l}\text { Medial } \\
\text { vowel }\end{array}$} & \multirow{2}{*}{$\begin{array}{c}\text { Final } \\
\text { consonant }\end{array}$} & \multicolumn{3}{|c|}{ Noise level } \\
\hline & & Quiet & $+6 \mathrm{~dB}$ & $+3 \mathrm{~dB} c$ & & & & Quiet & $+6 \mathrm{~dB}$ & $+3 \mathrm{~dB} C$ & & & & Quiet & $+6 \mathrm{~dB}$ & $+3 \mathrm{~dB}$ \\
\hline \multirow[t]{5}{*}{ k } & a & 24.32 & 13.04 & 3.23 & $p^{*}$ & 0 & & 8.11 & 16.33 & 8.96 & $\eta$ & $\mathrm{i}$ & $n$ & 28.07 & 28.33 & 6.00 \\
\hline & $\varepsilon$ & 11.11 & 12.82 & 6.78 & & u & & 13.79 & 25.93 & 23.61 & & & I & 10.64 & 8.00 & 5.97 \\
\hline & 0 & 5.26 & 21.21 & 5.45 & & i & & 21.57 & 30.14 & 11.11 & & & $\mathrm{~m}$ & 2.50 & 19.12 & 6.90 \\
\hline & u & 17.39 & 12.50 & 7.55 & s & a & & 18.42 & 20.69 & 13.64 & & & $p$ & 4.88 & 17.65 & 7.41 \\
\hline & i & 10.53 & 18.33 & 10.34 & & $\varepsilon$ & & 8.51 & 19.35 & 10.77 & & & s & 15.91 & 23.53 & 19.30 \\
\hline \multirow[t]{5}{*}{$k^{*}$} & a & 11.32 & 9.84 & 3.45 & & o & & 37.50 & 18.87 & 14.75 & & & $\eta$ & 10.53 & 19.05 & 18.18 \\
\hline & $\varepsilon$ & 10.00 & 13.64 & 6.56 & & u & & 15.56 & 21.82 & 14.75 & t6 & a & & 13.73 & 6.38 & 3.28 \\
\hline & 0 & 13.16 & 10.34 & 14.29 & & i & & 29.41 & 20.37 & 31.34 & & $\varepsilon$ & & 9.76 & 44.09 & 20.00 \\
\hline & u & 25.00 & 19.40 & 12.50 & $s^{*}$ & a & & 17.65 & 12.90 & 5.36 & & 0 & & 10.53 & 12.31 & 13.56 \\
\hline & $\mathrm{i}$ & 17.65 & 23.21 & 13.73 & & 0 & & 9.43 & 14.55 & 6.67 & & u & & 7.69 & 11.48 & 10.34 \\
\hline \multirow[t]{5}{*}{$n$} & a & 19.05 & 10.17 & 1.49 & & $\mathrm{u}$ & & 17.07 & 15.69 & 18.52 & & i & & 15.00 & 17.39 & 8.33 \\
\hline & $\varepsilon$ & 26.19 & 15.28 & 13.21 & & i & & 10.00 & 15.52 & 17.14 & $t_{6}^{*}$ & a & & 19.57 & 18.97 & 8.93 \\
\hline & 0 & 5.00 & 21.21 & 8.62 & $\eta$ & a & & 18.60 & 13.56 & 9.68 & & $\varepsilon$ & & 15.38 & 26.98 & 17.86 \\
\hline & u & 15.00 & 25.86 & 10.53 & & & k & 20.00 & 13.11 & 6.38 & & 0 & & 9.30 & 14.29 & 10.00 \\
\hline & i & 15.79 & 12.28 & 16.36 & & & $n$ & 15.56 & 17.54 & 2.13 & & u & & 7.69 & 16.92 & 8.20 \\
\hline \multirow[t]{5}{*}{$t$} & a & 13.16 & 8.70 & 16.18 & & & 1 & 6.38 & 16.00 & 7.69 & & i & & 2.86 & 12.00 & 9.43 \\
\hline & $\varepsilon$ & 5.13 & 11.48 & 11.54 & & & $\mathrm{~m}$ & 19.51 & 14.29 & 7.41 & $t 6^{h}$ & a & & 11.90 & 12.96 & 6.67 \\
\hline & 0 & 16.00 & 13.04 & 2.00 & & & $p$ & 16.22 & 18.46 & 16.00 & & $\varepsilon$ & & 20.93 & 15.09 & 11.11 \\
\hline & u & 11.43 & 27.69 & 19.67 & & & s & 5.56 & 21.15 & 5.71 & & 0 & & 10.00 & 26.00 & 1.96 \\
\hline & i & 15.79 & 17.74 & 17.86 & & & $\eta$ & 8.33 & 25.00 & 14.29 & & u & & 17.02 & 14.89 & 12.50 \\
\hline \multirow[t]{5}{*}{$t^{*}$} & a & 17.78 & 15.15 & 14.94 & & $\varepsilon$ & & 6.67 & 13.33 & 11.59 & & i & & 18.37 & 25.76 & 17.65 \\
\hline & $\varepsilon$ & 25.64 & 29.41 & 9.09 & & & k & 10.26 & 13.33 & 15.25 & $k^{h}$ & a & & 13.51 & 33.78 & 12.50 \\
\hline & 0 & 11.11 & 12.73 & 9.68 & & & $p$ & 15.00 & 23.64 & 8.33 & & 0 & & 8.11 & 17.65 & 20.37 \\
\hline & u & 22.92 & 17.31 & 21.54 & & 0 & & 2.38 & 32.84 & 7.58 & & u & & 19.57 & 35.71 & 14.86 \\
\hline & i & 18.92 & 29.79 & 18.57 & & & k & 15.38 & 21.05 & 11.48 & & i & & 13.04 & 9.52 & 6.90 \\
\hline \multirow[t]{4}{*}{ I } & a & 14.63 & 14.55 & 7.94 & & & $n$ & 31.43 & 16.36 & 11.76 & $t^{h}$ & a & & 33.33 & 13.04 & 13.04 \\
\hline & 0 & 21.74 & 38.36 & 21.88 & & & I & 12.20 & 18.75 & 9.59 & & $\varepsilon$ & & 21.62 & 18.03 & 19.35 \\
\hline & u & 18.60 & 23.33 & 27.69 & & & $\mathrm{~m}$ & 17.78 & 20.00 & 14.04 & & 0 & & 16.28 & 18.46 & 8.82 \\
\hline & $\mathrm{i}$ & 24.32 & 28.07 & 14.04 & & & $p$ & 21.05 & 8.16 & 18.64 & & $\mathrm{u}$ & & 18.92 & 30.00 & 8.77 \\
\hline \multirow[t]{5}{*}{$\mathrm{m}$} & a & 12.50 & 22.03 & 5.66 & & & s & 20.93 & 16.00 & 7.55 & & i & & 14.63 & 17.86 & 9.43 \\
\hline & $\varepsilon$ & 6.82 & 28.00 & 12.28 & & & $\eta$ & 13.95 & 23.40 & 12.28 & $p^{h}$ & a & & 12.50 & 22.00 & 9.33 \\
\hline & o & 12.12 & 7.81 & 5.36 & & u & & 8.33 & 28.21 & 12.96 & & $\varepsilon$ & & 12.20 & 20.69 & 10.61 \\
\hline & u & 22.00 & 20.31 & 20.37 & & & k & 10.53 & 15.38 & 5.88 & & 0 & & 16.67 & 17.54 & 14.04 \\
\hline & i & 26.00 & 8.62 & 2.86 & & & $n$ & 9.30 & 41.57 & 11.67 & & $\mathrm{u}$ & & 20.41 & 12.77 & 22.03 \\
\hline \multirow[t]{5}{*}{$p$} & a & 12.00 & 16.67 & 13.56 & & & I & 22.00 & 15.00 & 20.00 & & i & & 13.51 & 9.38 & 12.20 \\
\hline & $\varepsilon$ & 14.29 & 16.07 & 11.94 & & & $\mathrm{~m}$ & 12.20 & 20.69 & 9.52 & $\mathrm{~h}$ & a & & 13.04 & 15.25 & 5.17 \\
\hline & o & 10.87 & 20.34 & 15.49 & & & $p$ & 24.32 & 22.81 & 23.33 & & $\varepsilon$ & & 12.50 & 11.86 & 11.11 \\
\hline & u & 24.24 & 25.00 & 10.34 & & & s & 12.12 & 18.97 & 18.52 & & o & & 2.08 & 19.15 & 10.53 \\
\hline & i & 22.22 & 12.73 & 3.08 & & & $\eta$ & 26.09 & 12.50 & 10.53 & & $\mathrm{u}$ & & 11.11 & 19.05 & 9.09 \\
\hline$p^{*}$ & a & 13.51 & 12.90 & 5.56 & & i & & 6.67 & 17.31 & 26.98 & & i & & 13.51 & 18.03 & 17.46 \\
\hline & $\varepsilon$ & 4.76 & 16.36 & 11.76 & & & k & 16.67 & 11.59 & 16.39 & & & & & & \\
\hline
\end{tabular}

